\title{
Risk of climate-induced damage in historic parchment
}

\author{
Leszek Krzemień, Agata Czyżewska, Magdalena Soboń, Roman Kozłowski and Łukasz Bratasz* (0)
}

\begin{abstract}
Moisture adsorption and related dimensional change were examined in several samples of historic and contemporary parchment. The tensile behaviour was determined for contemporary parchment and two selected historic materials. The moisture-related data for most parchments are close to the contemporary material while aging and past treatments may lower adsorption of moisture and, in consequence, the dimensional change induced by changes in the moisture content. Contemporary parchment exhibited larger water vapour adsorption and moisture-related response compared to most historic materials and, therefore, can be regarded as the worst-case material in terms of the climate-induced risks to parchment. Tensile parameters of parchment varied significantly with increasing relative humidity $(\mathrm{RH})$. Elasticity modulus declined from on average 1200 to $400 \mathrm{MPa}$ and strain at failure doubled when $\mathrm{RH}$ increased from 30 to 85\%. Parchment's critical strain at which permanent deformation occurred decreased dramatically with increasing $\mathrm{RH}$ reaching zero at $80 \%$. Irreversible curling produced by variations in $\mathrm{RH}$ to which flat parchment specimens were subjected were measured by scanning the specimen surface with the use of a laser triangulation sensor. The degree of curling was expressed quantitatively as standard deviation of local curvatures in the parchment sheet. The study opens a perspective of using the relationship between degree of curling and magnitude of $\mathrm{RH}$ variations to derive categories of risk to parchment from indoor climate variations, under the condition that quantitative loss of aesthetical/display value of parchment objects resulting from increased curling is agreed. Historical parchment documents generally demonstrating considerable curling engendered by uncontrolled storage conditions in the past are not vulnerable to further distortion when subjected to variations in RH even of considerable magnitude.
\end{abstract}

Keywords: Parchment, Climate, Relative humidity, Damage, Adsorption, Dimensional response, Tensile properties, Curling

\section{Introduction}

Parchment can be defined as animal skins that have been dried under tension to produce a stiff, sheet material with a flat writing surface [1]. Dried, stretched skins were used for writing purposes already in the antiquity and the Dead Sea scrolls found in Qumran are most widely known of such writing substrate [2]. However, only soaking in slaked lime (liming process) introduced into the parchment making from the second half of the first millennium

\footnotetext{
*Correspondence: ncbratas@cyf-kr.edu.pl

Jerzy Haber Institute of Catalysis and Surface Chemistry, Polish Academy

of Sciences, Niezapominajek 8, 30-239 Kraków, Poland
}

$\mathrm{AD}$ allowed high-quality parchment of pale-grey to white colouring and flat, even surface to be produced in Islamic and European cultures. In Europe, parchment was the only writing medium until paper became widely available in the fourteenth/fifteenth century but the material has continued to be used for various purposes until our times. The period when parchment use was predominant in Europe left in libraries and archives many millions of parchment sheets used to produce legal, financial or political records, works of art as well as books and their covers, all of great historical value.

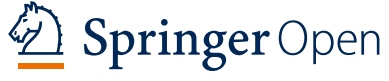

(c) The Author(s) 2020. This article is licensed under a Creative Commons Attribution 4.0 International License, which permits use, sharing adaptation, distribution and reproduction in any medium or format, as long as you give appropriate credit to the original author(s) and the source, provide a link to the Creative Commons licence, and indicate if changes were made. The images or other third party material in this article are included in the article's Creative Commons licence, unless indicated otherwise in a credit line to the material. If material is not included in the article's Creative Commons licence and your intended use is not permitted by statutory regulation or exceeds the permitted use, you will need to obtain permission directly from the copyright holder. To view a copy of this licence, visit http://creativeco mmons.org/licenses/by/4.0/. The Creative Commons Public Domain Dedication waiver (http://creativecommons.org/publicdomain/ zero/1.0/) applies to the data made available in this article, unless otherwise stated in a credit line to the data. 
Skins from sheep, goats or calves of which parchment generally has been produced consist of three layers: outer hair or grain layer, the medium corium layer and the inner flesh layer. When preparing skins for parchment, the two outer layers were scraped and the corium layer was split off for use as it provided the best characteristics for writing. Generally, two kinds of parchment-either 'hair-split' or 'flesh-split'-were produced depending on the extent to which each of the two outer layers were removed. The hair-split parchment had more grain layer, was usually thicker and stronger and had harder surface on the hair side. The flesh-split parchment with less grain layer was softer, and could receive ink on either side which was of advantage in book production (Fig. 1).

Parchment consists almost entirely of collagen fibrils forming a two-dimensional feltwork. Micro-focus X-ray diffraction images taken over parchment's cross section revealed that the fibrils are aligned parallel to the parchment surface and that this orientation is relatively uniform throughout the section [3]. A range of X-ray diffraction techniques was also used to examine structural changes in the collagen feltwork during parchment manufacturing process involving removal of hair, fats and other non-collagenous macromolecules [4]. Generally, the collagen structure and hierarchy, although weakened, are stable. The intramolecular interactions in the collagen molecules remain unaffected, though intermolecular lateral packing distance between these molecules and their axial staggered array change. The manufacturing process, especially the removal of non-collagenous material, brings about an expansion-'opening out'-of the collagen fibres, in particular an increase in the average fibril diameter and the fibril-to-fibril distance in a fibre.

Collagen tissues interact with water molecules gained from the vapour phase, and especially when immersed in liquid water. Hydration as well as moisture-related

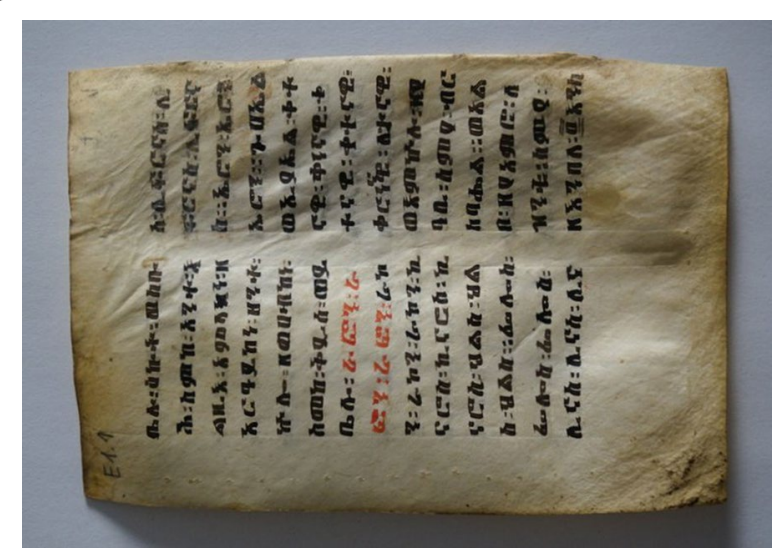

Fig. 1 Sheet of flesh-split parchment from a nineteenth century Abyssinian book swelling of collagen fibrils and their assemblies into biological tissues were researched experimentally and interpreted in terms of the microstructural changes $[5,6]$. The most comprehensive picture of these changes is obtained when moisture sorption is carried out from the vacuumdry state in which water is removed from the inter- and extrafibrillar spaces. The spacing between triple-helical collagen molecules in fibrils in this state is approximately $1.1 \mathrm{~nm}$ as determined by X-ray diffraction of animal tendons in which the collagen fibrils are aligned along one direction. Upon wetting, water is first accommodated in the intermolecular porosity in fibres amounting to $12 \%-$ gaps between collagen molecules resulting from their packing in fibrils in a staggering way. Once these axially oriented pores are filled with water, the lateral spacing between collagen molecules increases upon continuous water uptake reaching the 'saturation' value of approximately $1.4 \mathrm{~nm}$ that is to say a variation of more than $30 \%$ between the dry and the fully hydrated state. In contrast, full hydration-induced axial swelling is merely $5 \%$ and collagen fibres can be considered approximately dimensionally stable in the axial direction. The fibrillar swelling is accompanied by a proportional growth of the extrafibrillar space in the tissue until the full hydration of the fibres. Upon further water uptake only the extrafibrillar volume continues to grow.

Comparison of experimentally determined water vapour sorption isotherms for contemporary and historic parchment specimens with the overall mechanism of collagen tissue hydration summarized above allows water-collagen relation in parchment to be interpreted over a wide $\mathrm{RH}$ range from the dry state to humid conditions. The moisture content in parchment at $95 \% \mathrm{RH}$, that is to say close to the water vapour saturation pressure, is approximately $45 \%$ [7], half way to collagen fibre saturation level of $82 \%$. In turn, 'air-dried' parchment at $50 \% \mathrm{RH}$ contains approximately $10 \%$ of water, close to 9.6\% moisture content related to axially oriented porosity engendered by collagen molecules packing in fibres. Certain evolution in the water adsorption data for historic parchment has been observed and related to aging processes in collagen, involving hydrolysis, oxidation and gelatinization-loss of structural order. Generally, content of water decreases with aging. A solid-state NMR study of parchment established a correlation between increased structural disorder manifested by broadening of the ${ }^{13} \mathrm{C}$ signal and decreasing water content established from ${ }^{1} \mathrm{H}$ lineshape and relaxation time measurements [8].

Research into climate-related issues of the preservation of historic parchment has so far almost exclusively focused on chemical degradation of collagen within parchment. Thermal methods are used extensively to characterize the chemical integrity of collagen: 
differential scanning calorimetry [9] and, almost routinely, measurement of shrinkage temperature $T_{s}$ based on thermal denaturation of collagen fibres on heating which is observed under a microscope as deformation and shrinkage [10-12]. It is assumed that higher shrinkage temperatures correlate with more stable structure of collagen fibres, and consequently increased durability of parchment. The deterioration of fibrillar collagen thus assessed was used to study impact of temperature and relative humidity on parchment deterioration and in consequence to formulate evidence-based recommendations for the material preservation [9]. However, as the result of collagen moisture-related dimensional response, parchment objects shrink as they lose moisture and swell when they gain moisture, and they experience stress when restraint is placed on their dimensional response. Restraint may result from binding parchment sheets into a book block, attaching or partly attaching parchment with glue to rigid substrates (for example wooden or cardboard covers of books), or mounting a parchment sheet into a rigid housing (matting). Swelling of parchment restrained in its movement causes the material to curl whereas restrained shrinkage can additionally lead to physical failure if the tensile strain generated goes beyond the critical level [13]. Parchment sheets may also experience uneven moisture distribution and consequently patchy dimensional change. Water vapour transport into or out of a gathering of parchment records or sheets tightly bound in a book is not instantaneous resulting in a more pronounced moisture response of parchment at the edges. Oil or dirt deposits, for example from fingers of the readers at the edges or corners of manuscript volumes, can also block moisture transport compared to the surrounding material. Repairs may respond differently from the material repaired. The stress induced by the uneven response will manifest by a considerable distortion, typically curling.

Though, as described earlier, moisture-related dimensional change of collagen fibrils and their assemblies were researched experimentally and interpreted in terms of microstructural models, no information to our knowledge exists on how swelling or shrinkage of collagen fibrils transforms into the response of their two-dimensional feltwork forming parchment. No information is either available on the critical levels of strain at which parchment begins to irreversibly deform/curl, or fracture. The gap in sound information on the issues is reflected in the most up-to-date ISO standard on document storage requirements for archive and library materials which does not specify any storage specifications for parchment [14]. To assess experimentally the risk of physical damage to parchment caused by indoor climate variations, the relationships between $\mathrm{RH}$, moisture content and dimensional change were investigated in this study for a selection of flesh-split, thin historic and contemporary parchments. The moisture-related strains were compared with critical strains obtained in tensile tests. Parchment documents are predominantly composite objects made of inks, paints or gold leaf on the parchment substrate. Although inks or decorative layers affect the way in which parchment responds to climate variations, and these elements can experience damage as cracking or delamination, this study has focused on the parchment itself and no characterization and monitoring of inks or pigments were attempted. The study has to some extent followed the well-established methodology of quantifying the climate-induced damage of objects of fine and decorative art, predominantly decorated wood $[15,16]$ which methodology, however, has been refined to address broader patterns of damage, not only physical failure as fracture but also three-dimensional distortion like curls. It has been ambition of this study to contribute to the development of evidence-based environmental specifications for collections of library and archival objects.

\section{Materials and methods}

Seven historic samples of parchment were investigated. Samples of contemporary parchment produced in a manner similar to the historic material were also studied. Details of the materials are given in Table 1.

Moisture adsorption and desorption isotherms were determined at $24^{\circ} \mathrm{C}$ and for a range of $\mathrm{RH}$ between 0 and $80 \%$. The measurements were done gravimetrically with the use of a vacuum microbalance from CI Electronics, UK. Typically, a $0.1 \mathrm{~g}$ piece of a material was weighed and outgassed prior to a measurement under a vacuum of a residual pressure less than $0.1 \mathrm{~Pa}$. The aim was to eliminate water physisorbed during the storage of the sample-vacuum drying is a standard procedure in determining moisture content in heritage materials by the gravimetric method [17]. Vacuum was maintained until a constant weight was obtained, then subsequent portions of water vapour were introduced, and the respective mass increases due to the sorption and the respective equilibrium pressures were recorded. When the upper limit of the RH measuring range was reached, the desorption isotherm was recorded. Samples were considered to have reached an equilibrium when the weight changes were less than $0.05 \%$ in $40 \mathrm{~min}$. The equilibrium moisture contents were calculated on the basis of the initial weight of the out-gassed sample.

The dimensional change of parchment specimens accompanying water vapour adsorption and desorption was measured using strips $10 \times 50 \mathrm{~mm}^{2}$. The measurements were taken in a specially built sample holder placed in a vacuum vessel connected to the same outgassing and 


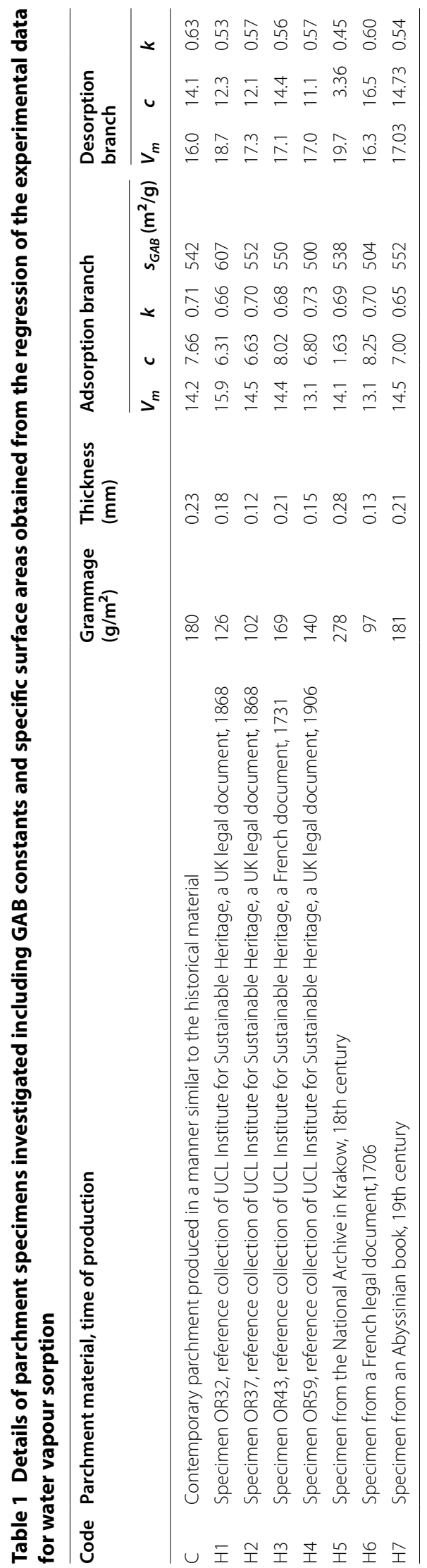


water vapour dosing system used to determine the water vapour sorption isotherms; in fact the two measurements were taken simultaneously. The specimen was vertically oriented in the holder and its upper end was firmly stabilised. The lower end was free to move in the vertical direction and changes of its position were measured with $2 \mu \mathrm{m}$ accuracy using an inductive transducer from RDP Electronics Ltd. The specimen was loaded with force of $0.8 \mathrm{~N}(80 \mathrm{~N} / \mathrm{m})$ sufficient to keep it in a vertical plane. Both expansion and shrinkage branches of the dimensional change isotherm were recorded.

The tensile properties were determined using a Universal Testing Machine (UTM) from Hegewald \& Peschke MPT GMBH for specimens of contemporary and historic parchments $100-140 \mathrm{~mm}$ long and $20 \mathrm{~mm}$ wide. All measurements were taken in a laboratory with temperature stabilized at $24{ }^{\circ} \mathrm{C}$ and several $\mathrm{RH}$ values between 25 and $90 \%$. Each sample was stabilized before the measurement for $2 \mathrm{~h}$. The rate of loading was $1 \mathrm{~mm} / \mathrm{min}$. To determine the tensile properties at loadings taking place over much longer time scale, samples were stretched instantly $(1 \mathrm{~mm} / \mathrm{s})$ to four consecutive fixed strain levels of $0.2,0.4,0.8$ and $1.6 \%$ and kept at each selected level for $2 \mathrm{~h}$. Then, the stress was released to the initial setting of the testing equipment (stress close to zero), and irreversible (permanent) deformation was measured after $6 \mathrm{~h}$. The test was repeated twice to determine if any additional permanent deformation occurred during the second cycle.

Furthermore, irreversible curling of parchment subjected to RH changes of increasing amplitudes was measured. Prior to the experiments, parchment specimens were gently humidified for up to $1 \mathrm{~h}$ in a damp pack with humid blotting paper separated from parchment by the Goretex fabric that blocked the contact with liquid water and allowed water vapour only to pass through. Then the specimens were dried in a flat form on a suction table. One edge of a parchment specimen measuring $210 \times 150 \mathrm{~mm}^{2}$ stabilized at $50 \% \mathrm{RH}$ was restrained in metal clamps. Then, the specimen was exposed to a given RH level and 50\% RH again. Samples were exposed to RH levels lower than $50 \%$ for $18 \mathrm{~h}$ and then stabilized at $50 \%$ for at least $48 \mathrm{~h}$. Samples were exposed to RH levels higher than $50 \%$ for $2 \mathrm{~h}$ and then stabilized at $50 \% \mathrm{RH}$ for $6 \mathrm{~h}$. After the selected time periods at $50 \% \mathrm{RH}$, the reversible curling was found to fade out and the irreversible curling could be measured. The curling was determined from a detailed metric 3D record of the specimen surface using a laser scanner. The scanner comprised a laser triangulation sensor measuring the distance between the sensor and the object in a fast, non-contact and precise way. The data were collected at a sampling interval of $1.4 \mathrm{~mm}$ along lines parallel to the clamps, the distances between the lines were of $7.5 \mathrm{~mm}$. Measurement uncertainty of the triangulation sensor was $\pm 0.005 \mathrm{~mm}$ in depth (z-axis) and approximately $\pm 0.05 \mathrm{~mm}$ in the $\mathrm{x}$ - and $\mathrm{y}$-axes. Then local curvature (approximated by a circle) in the direction parallel to the clamps was calculated for all points in the dataset recorded. The curling was expressed as standard deviation of all local curvatures.

\section{Results and discussion}

\section{Adsorption isotherms of water vapour}

For the selected RH range between 0 and $80 \%$, the relationship between the amount of the bound water and $\mathrm{RH}$ is described by a sigmoid shape of the type II isotherm in the IUPAC 1985 classification [18]. It indicates the monolayer-multilayer physisorption in which an adsorbed surface layer progressively thickens as the vapour pressure is increased up to saturation pressure. The sigmoid shape is characteristic of water adsorption isotherms for many natural materials, including parchment [7]. The Guggenheim-Andersen-de Boer (GAB) three-parameter sorption equation was used to describe the relationship between the amount of water adsorbed on parchment and $\mathrm{RH}$ :

$$
\begin{aligned}
& E M C(R H, T=\text { const. }) \\
& \qquad=\frac{V_{m} * c * k * R H / 100}{(1-k * R H / 100) *(1+(c-1) * k * R H / 100)}
\end{aligned}
$$

where EMC is the equilibrium moisture content in percent, $\mathrm{RH}$-relative humidity in percent, $V_{m}$-the monolayer capacity in the same units as EMC, $c$-an energy constant related to the difference of free enthalpy (standard chemical potential) of water molecules in the upper sorption layers and in the monolayer, and $k-$ the third parameter, related in turn to the difference of free enthalpy of water molecules in the pure liquid and the upper sorption layers. The GAB equation was demonstrated to describe the full shape of type II isotherm and yield meaningful physical parameters [19]. Therefore, the potential of GAB analysis has been explored to interpret experimental adsorption data of collagen materials [19-21].

The specific surface area $s_{G A B}$ is obtained from the monolayer capacity $V_{m}$ :

$$
s_{G A B}=V_{m} * \rho * N * \sigma / M
$$

where $M$ is the molar mass of water, $\rho$ is water density, $N$ is the Avogadro number and $\sigma$ is the average area occupied by one water molecule in the monolayer $-0.114 \mathrm{~nm}^{2}$ was used in this study.

By way of example, the experimental data for water vapour sorption by contemporary parchment are 


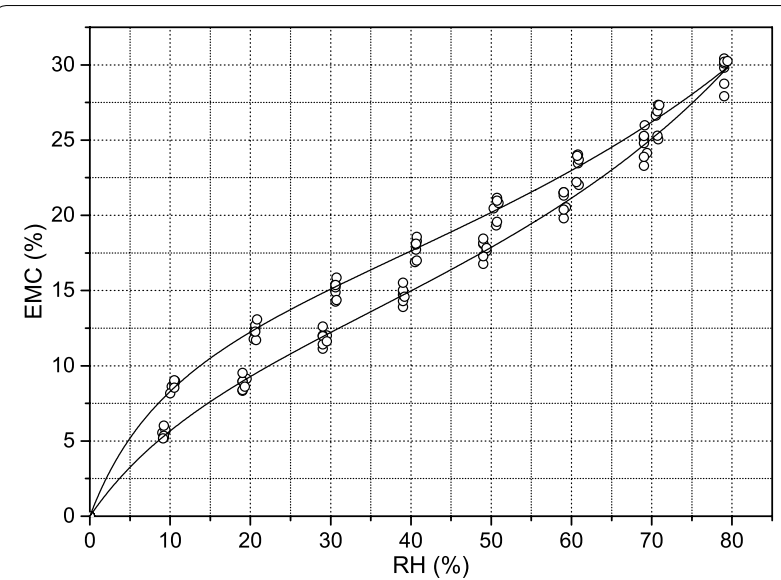

Fig. 2 Data from several measurements of water vapour adsorption and desorption (lower and upper branches, respectively) for specimens of contemporary parchment produced in a manner similar to the historic material are compared with the curves calculated from the least-square regression of the data to the GAB equation

compared in Fig. 2 with curves calculated using the GAB equation. For the desorption branch, the hysteresis effect is observed that is to say higher moisture content during desorption when compared to that during adsorption at any given $\mathrm{RH}$ value. This phenomenon is associated with the swelling of a non-rigid collagen structure in the course of adsorption so that the effect is in fact a manifestation of elastic hysteresis [18]. The GAB constants were determined by a least-squares regression of the GAB relation for $0 \%<\mathrm{RH}<80 \%$, which fully covers $\mathrm{RH}$ conditions relevant for the preservation of parchment. The regression was performed separately for the adsorption and desorption branches. It should be noted that the adsorption branch only yields meaningful monolayer capacity, and consequently specific surface area, owing to the hysteresis loop between the adsorption and desorption branches.

The GAB plots obtained from available experimental data for water vapour adsorption-for the sake of clarity, the adsorption branches only-are shown in Fig. 3 for all the specimens investigated. The GAB constants and $s_{G A B}$ values determined are contained in Table 1 . The moisture adsorption data for most parchments cluster close to those measured for the contemporary material. The lowest adsorption of moisture over the entire $\mathrm{RH}$ range was measured for specimen $\mathrm{H} 5$ coming from the eighteenth century book binding. The reason for the decreased water sorption by this specimen lied in a dramatic decrease in energy constant $c$ being approximately 1.6 for $\mathrm{H} 5$ when compared to the 6-8 range for the remaining specimens. The $c$ constant can be broadly interpreted free enthalpywise as a measure of 'affinity' of the adsorbed molecule to the adsorbing surface. Apparently, the parchment had undergone a treatment which reduced the hydrophilic

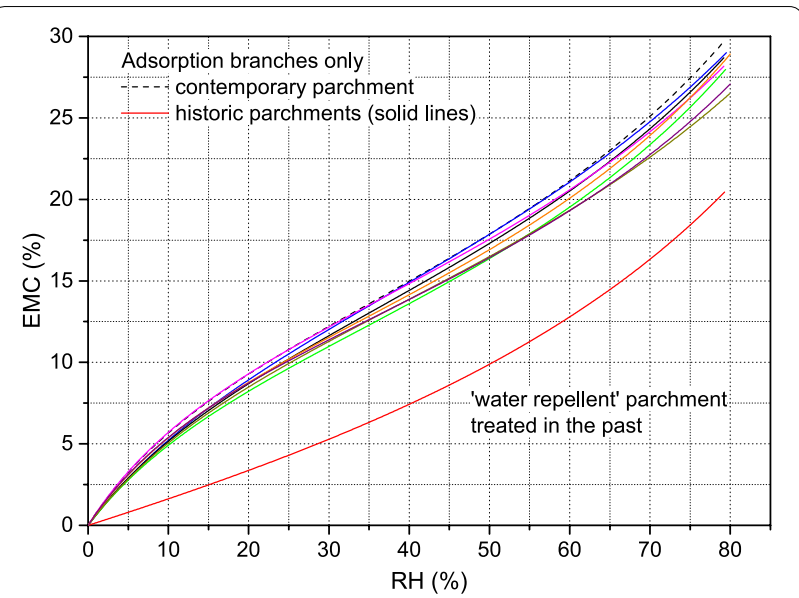

Fig. 3 Water vapour adsorption by all parchment specimens presented as plots calculated from the least-square regression of the experimental data to the GAB equation. The historic parchments dated to the eighteenth - early twentieth centuries (see Table 1)

character of the surface and weakened water-solid interactions. The contemporary parchment exhibited higher water vapour adsorption compared to most historic materials, the tendency documented in earlier studies reviewed in the introduction.

\section{Moisture-related strain}

The dimensional response of contemporary parchment loaded with $80 \mathrm{~N} / \mathrm{m}$ and subjected to a cycle of increase and decrease in the moisture content induced by the $\mathrm{RH}$ cycle between a dry condition and $80 \% \mathrm{RH}$ (see Fig. 2) is shown in Fig. 4. The moisture-related strain is expressed

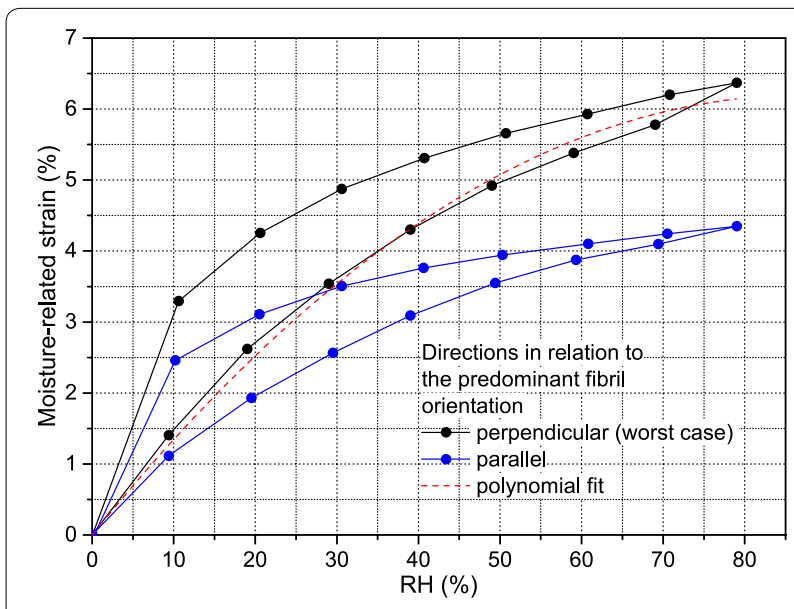

Fig. 4 Moisture-related strain—swelling and shrinkage (lower and upper branches, respectively) - in two perpendicular directions for a specimen of contemporary parchment subjected to an $\mathrm{RH}$ cycle between a dry condition and $80 \% \mathrm{RH}$ shown in Fig. 2. The curve calculated from the least-square regression of the upper swelling data to the second-order polynomial is also shown 
as the change in length divided by the specimen length at dry conditions $(\mathrm{RH}=0)$. The measurements were done in two perpendicular directions to take into account the possible effect of collagen fibre preferred orientation, and indeed the data demonstrate a difference in the moisturerelated dimensional change between the two directions. The swelling data can be described by the second order polynomial. No irreversible elongation was observed within an experimental error after the moisture adsorption-desorption cycle.

The strain vs RH relationships obtained from available swelling data by fitting the second-order polynomial are shown in Fig. 5 for all the specimens investigated. The constants determined are contained in Table 2. Larger responses were only considered in Fig. 5 and in the data set. Maximum moisture-related swelling of collagen fibres in the lateral direction, determined by X-ray diffraction of animal tendons in which the collagen fibrils are aligned along one direction, are provided for comparison (data from Table 1 in [5]). As one can see, there is no difference between the swelling data for collagen in parchments and in an animal tendon at $10 \% \mathrm{RH}$. The observation confirms the earlier findings described in the introduction that water is predominantly first accommodated in the axially oriented pores in the collagen fibres, with the lateral spacing between collagen molecules increasing only upon further water uptake.

As swelling is induced by the moisture adsorption, the swelling data for parchments are close to each other with the exception of specimen $\mathrm{H} 5$ which exhibited much lower adsorption of moisture over the entire $\mathrm{RH}$ range.

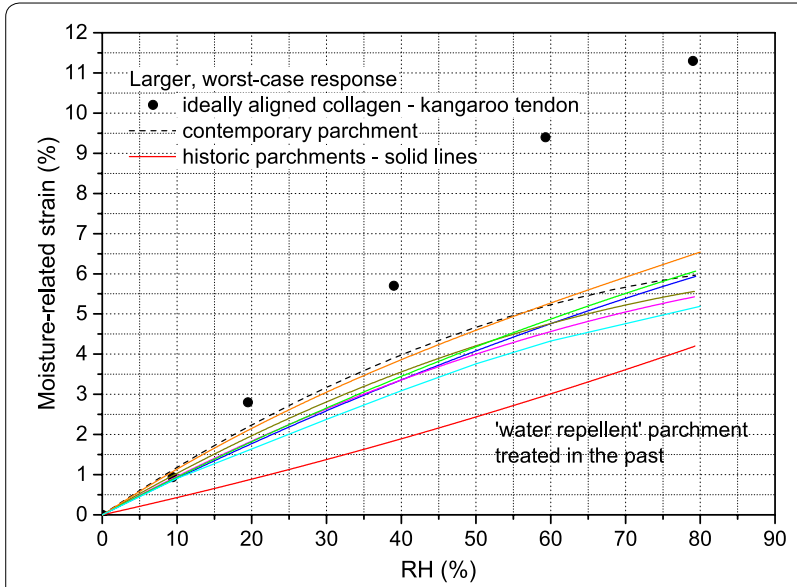

Fig. 5 Moisture-related swelling (data for directions of larger responses only) of all parchment specimens presented as plots calculated from the least-square regression of the experimental data to the second-order polynomial. Maximum moisture-related swelling of collagen fibres in the lateral direction, determined by X-ray diffraction of animal tendons, are provided. The historic parchments dated to the eighteenth — early twentieth centuries (see Table 1)
Table 2 Constants of second order polynomials obtained from the regression of the experimental data for moisturerelated swelling of parchment specimens-larger responses are only considered

\begin{tabular}{lrr}
\hline Code (see Table 1) & \multicolumn{1}{c}{$\boldsymbol{A}_{\mathbf{1}}$} & $\boldsymbol{A}_{\mathbf{2}}$ \\
\hline $\mathrm{C}$ & 12.43 & -6.19 \\
$\mathrm{H} 1$ & 9.33 & -2.33 \\
$\mathrm{H} 2$ & 10.80 & -4.77 \\
$\mathrm{H} 3$ & 9.96 & -3.93 \\
$\mathrm{H} 4$ & 9.60 & -2.47 \\
$\mathrm{H} 5$ & 4.16 & 1.44 \\
$\mathrm{H} 6$ & 11.24 & -3.92 \\
$\mathrm{H} 7$ & 8.99 & -3.10 \\
\hline
\end{tabular}

The equation used was $M R S=A_{1} \cdot R H+A_{2} \cdot R H^{2}$ where MRS is the moisture related strain in percent and $\mathrm{RH}$-relative humidity in percent. MRS is expressed as the change in length divided by the specimen length at dry conditions $(\mathrm{RH}=0)$, therefore the intercept of the polynomial function is zero

The contemporary parchment exhibited larger moisturerelated response compared to most historic materials, therefore can be regarded as the worst-case material in terms of the climate-induced risks to parchment.

\section{Tensile properties}

A typical stress-strain curve obtained at $50 \% \mathrm{RH}$ and the rate of loading of $1 \mathrm{~mm} / \mathrm{min}$ illustrates subsequent phases of the material deformation by increasing stress (Fig. 6). Strain is expressed as the change in length divided by the specimen original length and stress is calculated by dividing the force (load) applied to the test specimen by its cross-sectional area. The initial part of the curve-up to the strain of approximately $0.5 \%$ in Fig. $6-$ is almost linear and corresponds to the elastic response of the material. It was verified that-in this range-strain can be recovered completely on the

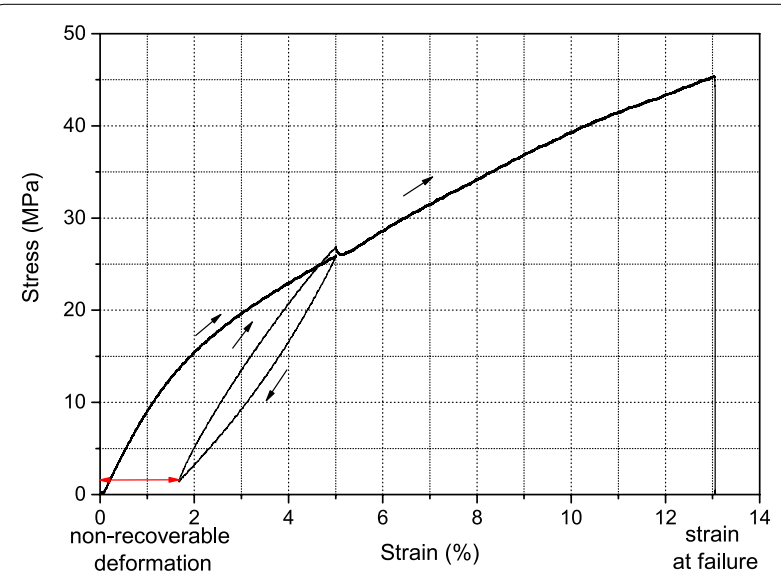

Fig. 6 Stress-strain curve for contemporary parchment measured at $50 \% \mathrm{RH}, 24^{\circ} \mathrm{C}$ and a loading rate of $1 \mathrm{~mm} / \mathrm{min}$ 
release of stress. Beyond the upper limit of the elastic range, the curve begins to deviate significantly from a straight line and non-recoverable plastic deformationon a release of stress-is observed. The final point on the stress-strain curve corresponds to an abrupt drop in load marking strain at which parchment fractures. Parchment must be stretched very considerably beyond the upper limit of the elastic range before the material fails via fracture (approximately 0.5 and $13 \%$, respectively). The experiments demonstrated that increasing $\mathrm{RH}$ produced softening of parchment illustrated by a considerable decrease in the elasticity modulus determined from the slopes of initial linear parts of the stress-strain plots (Fig. 7). The decrease in the modulus coincided with an increase in the parchment's strain at failure-understood

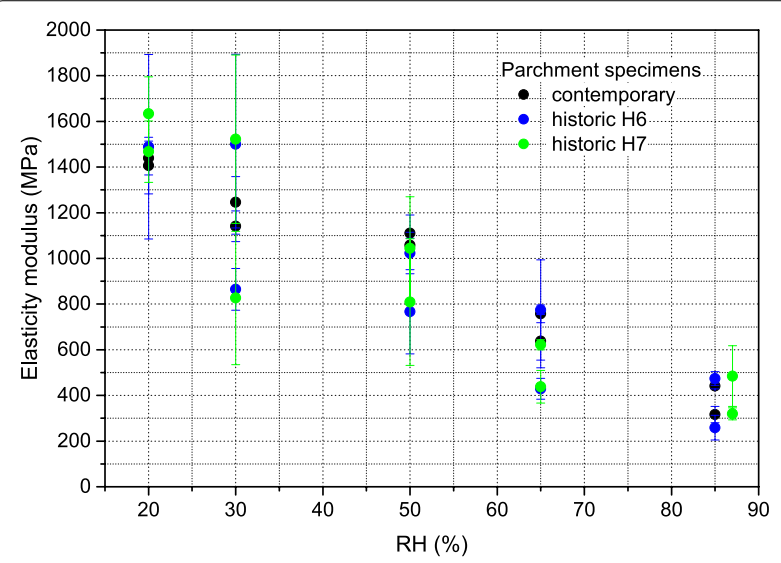

Fig. 7 Elasticity modulus of parchment specimens as a function of $\mathrm{RH}$. $\mathrm{H} 6$ and $\mathrm{H} 7$ specimens were taken from eighteenth century French and nineteenth century Abyssinian objects, respectively (see Table 1)

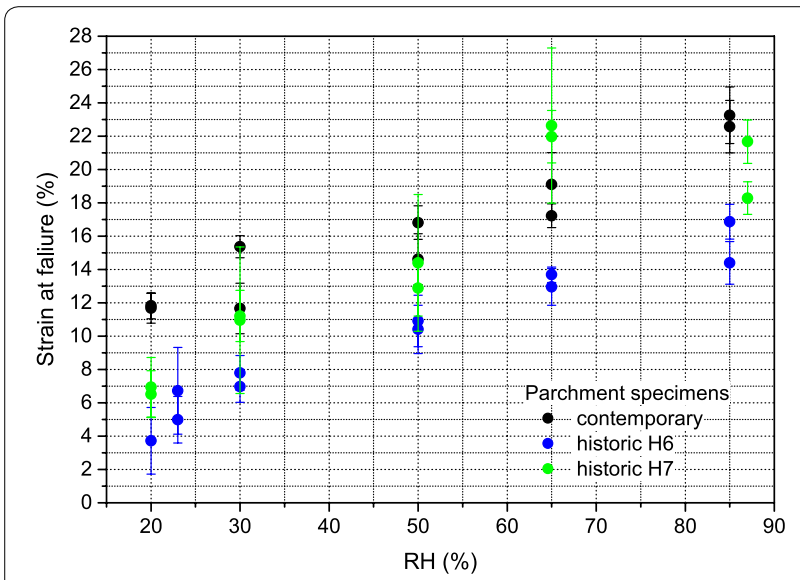

Fig. 8 Strain at failure of parchment specimens under tensile stress as a function of $\mathrm{RH}$. $\mathrm{H} 6$ and $\mathrm{H} 7$ specimens were taken from eighteenth century French and nineteenth century Abyssinian objects, respectively (see Table 1) as maximal extension before the material fractures-with increasing $\mathrm{RH}$, the parameter doubled between 30 and 90\% RH (Fig. 8).

The mechanical response of cultural materials, including parchment, depends on the rate at which the load is applied. Therefore, in the next stage of experiments, tensile properties were determined at loadings taking place over much longer time scale of up to $48 \mathrm{~h}$, rather than 15 min used in the fast tests described above. The longer time scale was compatible with the time scale of $\mathrm{RH}$ changes inducing stresses in parchment in real-world environments in museums or archives in which even short-term $\mathrm{RH}$ variations arising from weather changes outside, the opening and closing of doors and windows, the flow of visitors, or the intermittent operation of climate control systems range from hours to days. In the experiments, samples were stretched consecutively to four fixed strain levels of $0.2,0.4,0.8$ and $1.6 \%$ and kept at each level for $2 \mathrm{~h}$ during which the stress relaxation occurred to a great extent (Fig. 9). Then, the stress was released and, after a recovery period, the permanent deformation was measured. The plots of the permanent deformation versus the maximum strain level applied, obtained at RH of 50 and 63\%, demonstrate that the critical strain at which permanent deformation occurred-on slow loading which parchment is likely to experience in the real world environments-decreased to approximately 0.1 above $60 \%$ RH (Fig. 10). At $80 \%$ RH, this critical strain was close to zero that is to say parchment underwent permanent deformation at any strain applied. Phenomena such as the softening of parchment, the dramatic increase of its vulnerability to permanent deformation and the increase in the material's strain at failure under tensile stress, are the result of the bound

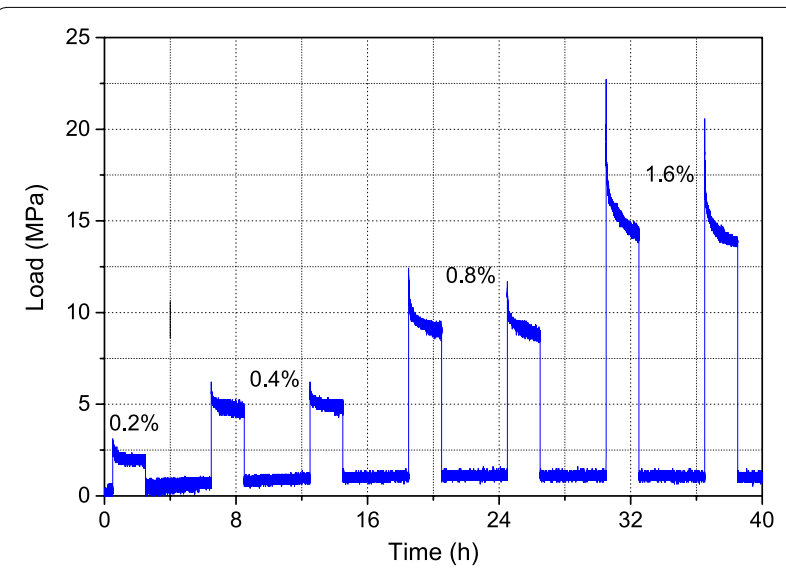

Fig. 9 Plots of load versus time for experiments in which parchment specimens were consecutively stretched to fixed strain levels of 0.2 , $0.4,0.8$ and $1.6 \%$ at $63 \% \mathrm{RH}$ 


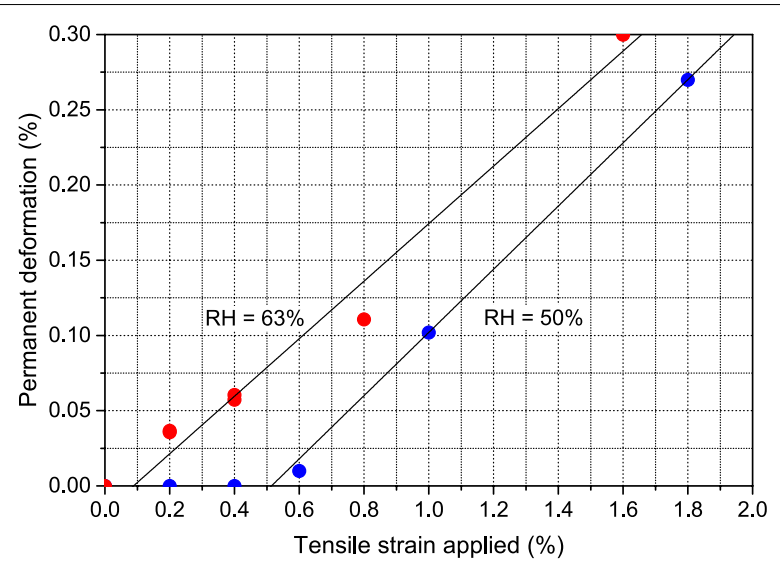

Fig. 10 Permanent deformation of parchment on stretching as a function of the maximum strain applied at $\mathrm{RH}$ of $50 \%$ and $63 \%$

water accommodating space within the collagen molecular matrix, increasingly filling and enlarging the intermolecular space.

\section{Moisture-related curling}

The observations provided above have demonstrated that strain at which permanent deformation of parchment on loading occurs becomes close to zero with increasing $\mathrm{RH}$. Therefore, the parameter poorly quantifies the climate-induced damage risk to parchment and a question arises as to what levels of irreversible physical change in the material can be perceived as 'unacceptable damage'. Parchment experiences stress when restraint is placed on its dimensional response and the restrained dimensional change causes the material to curl. Therefore, in the next stage of experiments, irreversible curling was measured for restrained parchment specimens subjected to $\mathrm{RH}$ changes of increasing magnitudes and stabilized back at $50 \% \mathrm{RH}$. At the outset of the experiments, parchment was almost flat and the curvature of some natural undulation left after the flattening treatment was negligible. Gently humidification of parchment sheets and their drying under tension has been a common approach in parchment conservation [1]. Therefore, the degree of irreversible curling induced by $\mathrm{RH}$ variations in an initially flat parchment sheet seemed a good measure of risk to parchment reflecting a frequent conservation problem. The sufficient exposition times were determined experimentally so that maximum curling was attained at $\mathrm{RH}$ levels different from $50 \% \mathrm{RH}$ on the one hand and the recovery of reversible curling was full when the specimens were stabilized back at 50\% RH before the irreversible curling was determined on the other.

The results for parchment specimens exposed to RH levels of 40, 30 and 20\% are shown in Fig. 11 as a

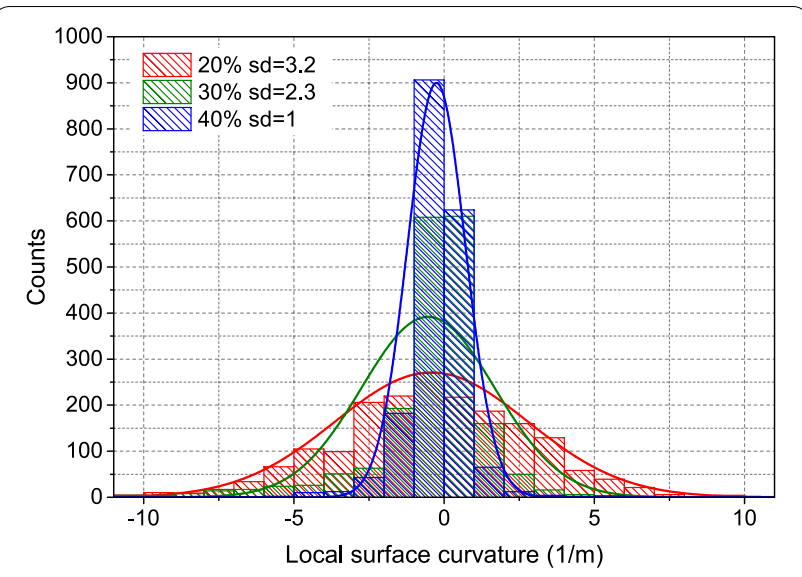

Fig. 11 Distribution of local surface curvatures measured in the direction parallel to the clamps for contemporary parchment specimens after they were exposed to RH levels of 40,30 and $20 \%$ for $18 \mathrm{~h}$ and then stabilized at 50\% for at least $48 \mathrm{~h}$. Standard deviation (sd) values calculated from the distributions are provided

distribution of surface curvature measured at all points of the specimen. The distribution has a characteristic Gaussian shape peaking around zero curvature with positive and negative deviations from a flat plane increasing with the increased distortion caused by falls in $\mathrm{RH}$ of increasing magnitudes. The acquired data were smoothed and a synthetic parameter characterizing parchment curling was calculated as standard deviation of local curvatures. The complete information on the irreversible curling produced by variations in $\mathrm{RH}$ to

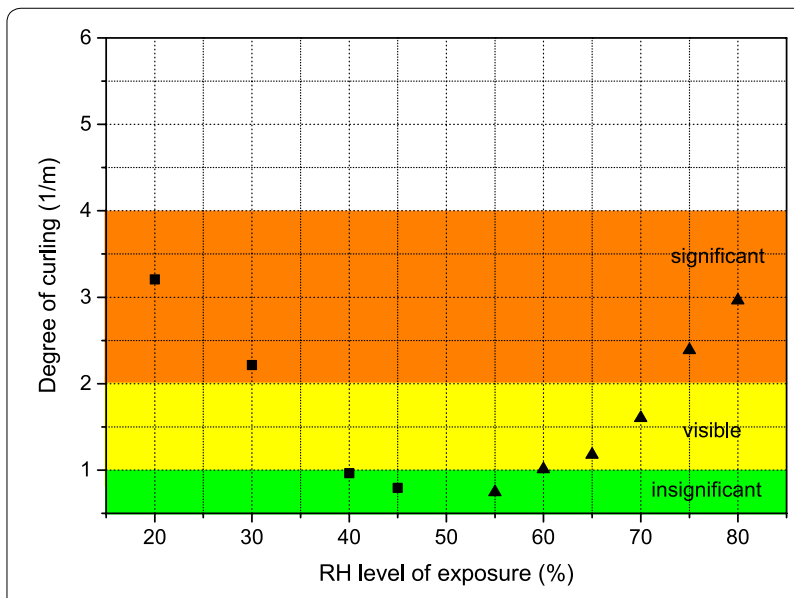

Fig. 12 Curling of contemporary parchment specimens_expressed as a standard deviation of local surface curvatures - after they were exposed to a given $\mathrm{RH}$ level and then stabilized back at $50 \% \mathrm{RH}$. Samples were exposed to $\mathrm{RH}$ levels lower than $50 \%$ for $18 \mathrm{~h}$ and then stabilized at $50 \%$ for at least $48 \mathrm{~h}$ (squares). Samples were exposed to $\mathrm{RH}$ levels higher than $50 \%$ for $2 \mathrm{~h}$ and then stabilized at $50 \% \mathrm{RH}$ for $6 \mathrm{~h}$ (triangles) 
which parchment specimens were subjected is shown in Fig. 12. The data make quantifying the risk of damage to parchment possible, by relating the degree of irreversible curling to risk indices. To illustrate the issue, three degrees of curling-insignificant, visible and significantwere arbitrarily selected as risk indices and marked with green, yellow and orange in Fig. 12. Obviously, further work with different stakeholder groups - the general public, curators, and conservators-is necessary to involve varying opinions on quantitative loss of aesthetic/display value of parchment objects resulting from increased curling.

Typically, historical parchment documents demonstrate considerable curling as they usually were storedduring their long history-in uncontrolled environments with large $\mathrm{RH}$ variations. In the next stage of experiments, specimens of historical parchment $\mathrm{H} 7$-one sheet used is shown in Fig. 1 as an example-were restrained and subjected to $\mathrm{RH}$ changes of increasing magnitudes and stabilized back at 50\% $\mathrm{RH}$ using the same experimental protocol as described above for the flattened contemporary parchment specimens. No further distortion of the sheets was observed as demonstrated by a constant degree of curling irrespectively of the magnitude of variations in $\mathrm{RH}$ to which the historical parchment had been subjected (Fig. 13). The observation points to the 'acclimatization' of parchment to indoor environments in which it was stored in the past. Michalski coined the term 'proofed fluctuation', defined as the largest RH fluctuation to which the object previously has been exposed [22]. He assumed that the risk of further physical damage from fluctuations smaller than the proofed values is

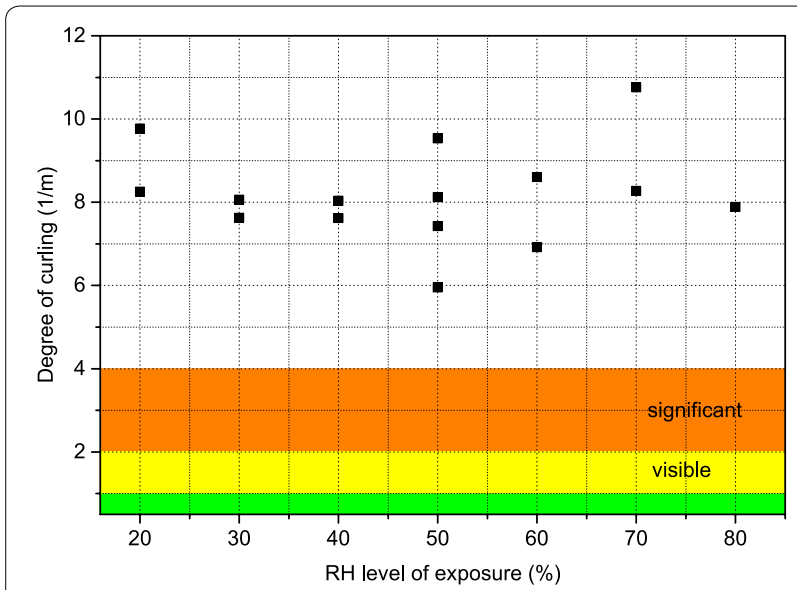

Fig. 13 Curling of historical parchment specimens from a nineteenth century Abyssinian manuscript $\mathrm{H} 7$ —expressed as a standard deviation of local surface curvatures-after they were exposed to a given $\mathrm{RH}$ level and then stabilized back at 50\% RH. Exposure times are the same as in the case illustrated in Fig. 12. The degree of curling of the historical specimens, prior to the experiments, are represented by points at $50 \% \mathrm{RH}$ low if the object and environment are not altered. If the past fluctuation was enough to cause distortion or damage, the object has undergone change, and the damage reduces the stress which would otherwise develop in the undamaged material.

\section{Conclusions}

There are several significant aspects of this study. Firstly, the analysis of the water sorption isotherms for contemporary and historic parchments-using the Guggenheim-Andersen-de Boer equation-has demonstrated that most parchments cluster close to the contemporary material, although aging and previous treatments may lower the adsorption of moisture. The contemporary parchment exhibited higher water vapour adsorption compared to most historic materials. As parchment swelling or shrinkage is induced by changes in moisture content, the swelling data for parchments clustered again close to those measured for the contemporary material which can be regarded as the worst-case material in terms of the climate-induced risk.

Tensile parameters of parchment-determining its vulnerability to physical damage-were found to vary significantly with increasing RH. Elasticity modulus declined from on average 1200 to $400 \mathrm{MPa}$ at 30 and $85 \% \mathrm{RH}$. The moisture-induced softening of the material coincided with parchment becoming easily deformable and strain at failure doubled when $\mathrm{RH}$ increased from 30 to $85 \%$. Most importantly, parchment critical strain at which permanent deformation occurred decreased dramatically reaching zero at $80 \% \mathrm{RH}$ that is to say parchment was found-at high $\mathrm{RH}$ conditions-to undergo irreversible deformation at any strain applied.

In view of very high vulnerability of parchment to moisture-induced irreversible deformation, irreversible curling produced by variations in $\mathrm{RH}$ to which flat parchment specimens were subjected was proposed as a measure of risk of damage. The degree of curling was determined from a detailed metric 3D record of the specimen surface using a scanner with a laser triangulation sensor measuring the distance between the sensor and the object. The relationship between degree of curling and magnitude of $\mathrm{RH}$ variations could be used to derive categories of risk to parchment caused by climate variations. Importantly, historical parchment documents, generally demonstrating considerable curling engendered by uncontrolled storage conditions in the past, are not vulnerable to further distortion when subjected to variations in $\mathrm{RH}$ even of considerable magnitude.

The findings of the study can provide a framework for gathering data on response of parchment objects in library and archive collections. A particularly important area for future research and conservation efforts is 
quantifying risk to parchment from climate variations. Moreover, correlation between chemical degradation of parchment revealed by thermal analysis data and/or molecular analysis of the material and its vulnerability to physical damage need to be clarified. A further correlation between the parchment distortion and risk of cracking and delamination of inks, paint layers and gold leaf needs to be established. On the other hand, various stakeholder groups-the general public, curators, and conservation professionals-need to explore quantitative loss of aesthetic/display value of parchment objects resulting from increased distortion such as curling.

\section{Abbreviations}

EMC: Equilibrium moisture content; GAB: Guggenheim-Andersen-de Boer; $\mathrm{RH}$ : Relative humidity.

\section{Acknowledgements}

Professor Matija Strlič is acknowledged for providing samples of historic parchments from the reference collection of the Institute for Sustainable Heritage, University College London for this research. The authors thank Antonina Kozłowska for her assistance with the measurements of moisture adsorption and moisture-related strain.

\section{Authors' contributions}

LK and AC determined tensile properties and climate-induced curling of parchment specimens. RK, ŁB and MS collected the specimens, conducted measurements of moisture adsorption and moisture-related strain and interpreted the results. RK wrote the first draft of the manuscript. All authors read and approved the final manuscript.

\section{Funding}

This research was funded in part by the statutory research fund of the Jerzy Haber Institute of Catalysis and Surface Chemistry, Polish Academy of Sciences. The work was supported by the Polish National Centre for Research and Development [Grant PBS2/A9/24/2013], the Polish National Agency for Academic Exchange [Grant PPN/PPO/2018/1/00004/U/00001] and the Getty Conservation Institute's Managing Collection Environments Initiative.

\section{Availability of data and materials}

The data used during the current study are available from the corresponding author on reasonable request.

\section{Competing interests}

The authors declare that they have no competing interests.

Received: 20 November 2019 Accepted: 4 February 2020

Published online: 17 February 2020

\section{References}

1. Woods CS. The conservation of parchment. In: Kite M, Thomson R, editors Conservation of leather and related materials. London: Routledge; 2005. p. 200-24.

2. Schütz R, Bertinetti L, Rabin I, FratzI P, Masic A. Quantifying degradation of collagen in ancient manuscripts: the case of the Dead Sea Temple Scroll. Analyst. 2013;138:5594-9.

3. Kennedy CJ, Hiller JC, Lammie D, Drakopoulos M, Vest M, Cooper M, Adderlay WP, Wess TJ. Microfocus X-ray diffraction of historical parchment reveals variations in structural features through parchment cross sections. Nano Lett. 2004;4:1373-80.

4. Maxwell CA, Wess TJ, Kennedy CJ. X-ray diffraction study into the effects of liming on the structure of collagen. Biomacromol. 2006;7:2321-6.

5. Morin C, Hellmich C, Henits P. Fibrillar structure and elasticity of hydrating collagen: a quantitative multiscale approach. J Theoret Biol. 2013:317:384-93.

6. Masic A, Bertinetti L, Schuetz R, Chang SW, Metzger TH, Buehler MJ, Fratzl P. Osmotic pressure induced tensile forces in tendon collagen. Nat Commun. 2015. https://doi.org/10.1038/ncomms6942.

7. Popescu CM, Hill CAS, Kennedy C. Variation in the sorption properties of historic parchment evaluated by dynamic water vapour sorption. J Cult Herit. 2016;17:87-94.

8. Aliev AE. Solid-state NMR studies of collagen-based parchments and gelatin. Biopolymers. 2005;77:230-45.

9. Badea D, Della Gatta G, Usacheva T. Effects of temperature and relative humidity on fibrillar collagen in parchment: a micro differential scanning calorimetry (micro DSC) study. Polym Degrad Stabil. 2012;97:346-53.

10. Improved Damage Assessment of Parchment (IDAP), Larsen R, editor. Research Report No 18. Brussels: European Commission; 2007.

11. Možir A, Kralj Cigić I, Marinšek M, Strlič M. Material properties of historic parchment: a reference collection survey. Stud Conserv. 2014;59:136-49.

12. Mühlen Axelsson K, Larsen R, Sommer DVP, Melin R. Degradation of collagen in parchment under the influence of heat-induced oxidation: preliminary study of changes at macroscopic, microscopic, and molecular levels. Stud Conserv. 2016;61:46-57.

13. Herringer SN, Bilheux HZ, Bearman G. Quantification of water absorption and transport in parchment. Phys Procedia. 2015;69:524-9.

14. ISO 11799:2015. Information and documentation-Document storage requirements for archive and library materials. Brussels: European Committee for Standardization; 2015.

15. Mecklenburg MF, Tumosa CS, Erhardt D. Structural response of painted wood surfaces to changes in ambient relative humidity. In: Dorge $\mathrm{V}$, Howlett FC, editors. Painted wood: history and conservation. Los Angeles: The Getty Conservation Institute; 1998. p. 464-83.

16. Bratasz $Ł$. Allowable microclimatic variations for painted wood. Stud Conserv. 2013:58:65-79.

17. EN 16682:2017. Conservation of cultural heritage-methods of measurement of moisture content, or water content, in materials constituting immovable cultural heritage. Brussels: European Committee for Standardization; 2017.

18. Sing KSW, Everett DH, Haul RAW, Moscou L, Pierotti RA, Rouquerol J, Siemieniewska T. Reporting physisorption data for gas solid systems with special reference to the determination of surface area and porosity. Pure Appl Chem. 1985;57:603-19.

19. Timmermann EO. Multilayer sorption parameters: BET or GAB values? Colloids Surf A. 2003;220:235-60.

20. Grigera JR, Berendsen HJC. The molecular details of collagen hydration. Biopolymers. 1979;18:47-57.

21. Manich AM, Maldonado F, Carilla J, Catalina M, Marsal A. Moisture adsorption/desorption of collagen. J Am Leather Chem As. 2010;105:229-41.

22. Michalski S. The ideal climate, risk management, the ASHRAE chapter, proofed fluctuations, and towards a full risk analysis model. A discussion paper presented at the Experts' Roundtable on Sustainable Climate Management Strategies, Tenerife, 2007. Los Angeles: The Getty Conservation Institute. http://www.getty.edu/conservation/our_projects/science/clima te/paper_michalski.pdf Accessed 6 Nov 2019.

\section{Publisher's Note}

Springer Nature remains neutral with regard to jurisdictional claims in published maps and institutional affiliations. 